\title{
Percepções de educadores sobre vínculos afetivos com crianças em acolhimento institucional
}

\author{
André Isaac da Silva Assunção* \\ Edson Junior Silva da Cruz** \\ Lilia Ieda Chaves Cavalcante*** \\ Janari da Silva Pedroso****
}

\begin{abstract}
Resumo
Este trabalho analisou as percepções de 10 educadores de duas instituições de acolhimento infantil sobre vínculos afetivos com crianças, na faixa etária de dois a seis anos. A investigação qualitativa ocorreu por meio de entrevista semiestruturada, composta por 10 questões discursivas. Os dados foram sistematizados a partir da técnica de análise de conteúdo de Bardin. O estudo demonstrou que as percepções dos educadores que foram analisadas divergiram sobremaneira em relação à impossibilidade da não criação de vínculos destes com as crianças e os prejuízos que esta ligação afetiva pode trazer para o trabalho desenvolvido na instituição, principalmente no momento em que se dá o retorno delas à convivência familiar. Concluiu-se que na percepção dos educadores esse processo de vinculação promove afeto, proximidade, afeição, zelo, angústia e sofrimento.

Palavras-chave: Crianças, acolhimento institucional, vínculos afetivos.
\end{abstract}

\section{Educators' perceptions about affective bonds with children in institutional care}

\begin{abstract}
This work analyzed the perceptions of 10 educators from two childcare institutions about affective bonds with children, aged between two and six years. The qualitative investigation took place through a semi-structured interview, composed of 10 discursive questions. The data were systematized using Bardin's content analysis technique. The study showed that the perceptions of the educators that were analyzed diverged greatly in relation to the impossibility of not creating bonds between them and the children and the losses that this affective bond can bring to the work developed at the institution, especially at the moment when it occurs, their return to family life. It was concluded that, in the educators' perception, this linking process promotes affection, closeness, affection, zeal, anguish and suffering. Keywords: Children, institutional acceptance, affective bonds.
\end{abstract}

* Universidade Federal do Pará- UFPA. Psicólogo e Mestre em psicologia pelo Programa de Pós Graduação em Psicologia pela Universidade Federal do Pará. andreisaacassuncao@gmail.com .

** Universidade Federal do Pará- UfPA. Psicólogo. Doutor e Mestre em Psicologia pelo Programa de Pós Graduação em Psicologia pela Universidade Federal do Pará.edsoncruzufpa@gmail.com .

*** Lilia Ieda Chaves Cavalcante. Universidade Federal do Pará- UFPA.Bolsista de Produtividade CNPq, professora da Faculdade de Serviço Social da Universidade Federal do Pará. Está credenciada como professora orientadora ao Programa de Pós-Graduação em Teoria e Pesquisa do Comportamento. É Mestre em Serviço Social e Doutora pelo Programa de Pós-Graduação em Teoria e Pesquisa do Comportamento da Universidade Federal do Pará, com Pós-Doutorado pelo Programa de Pós-Graduação em Psicologia da Universidade Federal do Rio Grande do Sul. liliaccavalcante@gmail.com .

**** Universidade Federal do Pará- UFPA. Bolsista de Produtividade CNPq. Professor Associado III da Faculdade de Psicologia da Universidade Federal do Pará. Doutor e Mestre em Ciências pelo Núcleo de Altos Estudos Amazônicos da UFPA, com Pós-Doutorado pelo Programa de Pós-Graduação em Psicologia da Universidade de Brasília. Docente do Programa Pós-Graduação em Teoria e Pesquisa do Comportamento e do Programa de Pós-Graduação em Psicologia. pedrosoufpa@gmail.com . 
A importância das relações primárias para o desenvolvimento emocional tem grande destaque na Teoria do Apego que é caracterizada a partir da relação do bebê com sua mãe ou cuidador, desde o nascimento até os seis anos de idade (Bowlby, 1969/2002). Bowlby enfatiza que a repetição do padrão das interações iniciais entre a mãe ou cuidador substituto e o bebê formará um modelo interno com o qual a criança irá constituir suas relações vindouras (Lemos, Gechele, \& Andrade, 2017).

A condição de dependência do bebê em relação ao seu cuidador tem destaque na teoria de Winnicott (1965/2001). Essa dependência é caracterizada por um momento de experiências necessárias para a consolidação de um vínculo afetivo e para a constituição dos traços de personalidade da criança. Dessa forma, a família, a mãe ou o cuidador substituto se mostram como essencial para elaboração dos estados emocionais da criança, o que vai interferir na integração das suas vivências e na relação com o meio em que se insere (Winnicott, 1965/2001).

Logo, o vínculo afetivo mostra-se na relação cuidador e criança como uma forma de subsistência e sustentação de um espaço adequado para o desenvolvimento sadio da díade. Tal contato afetivo funciona como busca por segurança e apoio, o que proporciona a aptidão funcional da personalidade da criança. A forma como são providas suas necessidades afetivas e ambientais, e a forma como são internalizadas, pode influenciar no desenvolvimento e na capacidade de vincular-se um ao outro (Cruz, Pedroso, \& Cavalcante, 2017; Lemos, Gechele, \& Andrade, 2017; Silva \& Neto, 2012).

Crianças que não tiveram cuidado afetivo e protetivos, possivelmente podem apresentar problemas de apego reativo. Tal condição pode está atrelada às condições de negligência que as mesmas foram expostas, como: o abandono e aspectos ligados à vulnerabilidade social (fome, condições de higiene e moradia precárias) (Cruz, Cavalcante e Pedroso, 2018). Assim, quando se pensa na criança em situação de acolhimento, há de se supor que em algum momento de sua trajetória houve ruptura no vínculo com algum membro familiar, sendo que muitas vezes, antes do acolhimento, tal vínculo já era frágil.

Nesse contexto, a instituição de acolhimento surge como uma medida protetiva capaz de oferecer suporte material e afetivo. No entanto, para isso, é importante que os cuidadores, responsáveis pela atenção junto a estas crianças, estejam disponíveis para gerar, nesse ambiente, um local de fortalecimento e construção de vínculos saudáveis (Golin \& Benetti, 2013; Silva \& Neto, 2012).

De acordo com o Conselho Nacional de Justiça (2020), até março de 2020 o país tinha 34.008 crianças e adolescentes acolhidos. Sendo que a região que mais concentra esse número é a Sudeste (15.900 acolhidos), seguida da região Sul (7.710 acolhidos). Mais de 60\% desses acolhidos são adolescentes e a divisão entre os gêneros é quase idêntica.

As crianças na fase da primeira infância - de zero a seis anos, juntas, somam 9,1 mil acolhimentos. Cerca de 2.400 bebês com até três anos aguardam até seis meses pelo retorno à família de origem ou pela adoção. Este é o tempo de permanência a que está submetida à maioria das crianças entre três e seis anos. Em números absolutos, o maior número de acolhidos encontra-se nos estados de São Paulo, Minas Gerais e Rio Grande do Sul. Já os estados do Acre, Roraima e Tocantins registram a menor quantidade de acolhidos (CNJ, 2020).

O novo painel do SNA informa também que, ao todo, são 56,8 mil vagas no acolhimento institucional, enquanto que, para acolhimento familiar, são 1,7 mil em todo Brasil. Os estados de Minas Gerais, Rio Grande do Sul e Santa Catarina destacam-se com a maior quantidade de acolhimentos familiares em território nacional.

Nos dados atuais não foram mencionados os principais motivos do acolhimento e nem o número de visitas que os acolhidos recebem, entretanto, no relatório anterior produzido pelo Conselho Nacional do Ministério Público (CNMP, 2013) foi apontado que a maior parte das instituições $(81 \%)$ reportou acolhimentos realizados em razão de negligência dos pais ou responsáveis. A segunda maior causa de acolhimento é a dependência por drogas ou álcool dos pais ou responsáveis (81\%), seguida pelo abandono $(78 \%)$, pela violência doméstica $(57 \%)$ e pelo abuso sexual (44\%).

O CNMP mostrou um dado preocupante no que diz respeito às visitas que as crianças recebiam durante o acolhimento institucional. Em $75 \%$ das entidades verificou-se a presença de acolhidos que não recebiam visitas há mais de dois meses. O acolhimento institucional de crianças e adolescentes é, segundo determina o ECA, uma medida de proteção, mas que pode imputar também perdas e prejuízos ao desenvolvimento infantil ou, ao contrário, favorecer para que essas crianças tenham um desenvolvimento adequado.

As instituições de acolhimento, de acordo com as políticas que embasam esses serviços, devem ter um 
clima residencial, configurado por uma moradia digna, com atendimento personalizado, bem como deve ser uma medida de caráter provisório. Quando há necessidade de acolhimento, busca-se a sustentação dos vínculos com a família, priorizando a reintegração junto à família de origem ou extensa (Lemos \& Silva, 2019). Somente após a destituição do poder familiar é que existe o encaminhamento para adoção (Brasil, 1990). Diversos fatores influenciam no fortalecimento ou na fragilidade dos vínculos como: a qualidade do cuidado antes e durante o acolhimento, a idade em que a criança foi acolhida, a qualidade do ambiente antes e durante a institucionalização e a disponibilidade da díade cuidador- criança para interagir (Cruz, Cavalcante, \& Pedroso, 2018).

Em um local de cuidados compartilhados, a forma de cuidar se difere do ambiente familiar em que os pais ou cuidador de referência exerce uma atenção mais individualizada à criança (Kappler \& Mendes, 2019), entretanto a expressividade e interação da criança com o ambiente vai se distinguir e formar sua individualidade e identidade. Nesse ponto, os educadores são responsáveis pela organização de condições que favoreçam esse processo de formação pessoal da criança (Cecílio, Borges \& Scorsolini-Comin, 2018; Kappler \& Mendes, 2019).

Os educadores têm uma presença mais marcante na rotina das crianças, visto que são responsáveis pelo acolhimento às suas necessidades, como almoço, banho e tarefas escolares (Cruz, Cavalcante \& Pedroso, 2018; Kappler \& Mendes, 2019; Medeiros \& Martins, 2018). O educador social pode ser considerado uma figura de referência e seu trabalho deve ir além de auxiliar e direcionar as crianças para atividades rotineiras. Siqueira e Dell'Aglio (2006) argumentam que as relações estabelecidas com as figuras de cuidado têm papel central na vida da criança.

Por se tratar de um espaço coletivo é comum que as decisões sejam tomadas levando-se em consideração o grupo e não somente um indivíduo em particular e, por isso, muitas vezes, as crianças são impedidas de fazerem escolhas pessoais (Magalhães, Costa, \& Cavalcante, 2011). $\mathrm{O}$ acolhimento institucional pode oferecer à criança e ao adolescente aspectos protetivos e promotores de bem-estar, como a probabilidade de construção de novos vínculos afetivos com pares, educadores sociais e demais funcionários (Cruz, Cavalcante \& Pedroso, 2018; Medeiros \& Martins, 2018). Desse modo, o objetivo deste estudo foi analisar a percepção de educadores de duas instituições de acolhimento infantil sobre os vínculos afetivos com crianças em acolhimento institucional.

\section{Método}

Delineamento: acentuar o caráter exploratório do estudo

\section{Participantes}

Participaram 10 educadores de um total de 27 profissionais responsáveis pelo cuidado de crianças de dois a seis anos em duas instituições de acolhimento localizadas na região metropolitana de Belém do Pará. Os critérios de inclusão da pesquisa foram: que fossem educadores, com tempo mínimo de atuação de 30 dias no serviço de acolhimento institucional, que atuassem no cuidado de crianças de dois a seis anos e que tivessem conhecimento da rotina de cuidado dentro da instituição. Os critérios de exclusão foram: educadores que atuassem apenas com crianças de faixa etária abaixo dos dois anos e crianças que estivessem fora da faixa etária escolhida e apresentassem algum diagnóstico de alguma deficiência ou transtorno mental. (Ver tabela 1).

\section{Local de coleta}

As instituições " $\mathrm{A}$ " e "B" foram escolhidas por terem em seus quadros educadores de crianças. $\mathrm{Na}$ instituição A, as entrevistas ocorreram na sala com a permanência de algumas crianças da instituição. A casa era regida por entidade municipal, com criança de zero a seis anos, além do mais, no local trabalhavam 14 educadores do sexo feminino com atuação de dois ou três turnos, em regime de 12 horas por 36 horas. Na instituição B, as entrevistas foram realizadas em uma sala de jogos, sem a presença de crianças. Trabalhavam 13 educadores em regime de plantão $12 \mathrm{~h}$ por $36 \mathrm{~h}$ (seis educadores no plantão diurno e seis no plantão noturno) e contavam ainda com uma educadora de referência que trabalhava de segunda à sexta de $13 \mathrm{~h}$ às $19 \mathrm{~h}$, três do sexo masculino e 10 do sexo feminino.

\section{Entrevista semiestruturada}

Roteiro de entrevista composto por 10 questões abertas, com temas referentes ao conhecimento sobre o acolhimento institucional, experiência de cuidado e vínculos afetivos. O instrumento incluía questões como: identificação pessoal dos educadores, dados sociodemográficos e tempo de serviço de acolhimento. O roteiro foi construído pelos autores com base na literatura existente sobre a temática. 
Tabela 1. Perfil Sociodemográfico dos educadores

\begin{tabular}{l|c|l|l|l|l|l|l}
\hline Educador & Idade & Escolaridade & Situação funcional & Tempo de serviço & Filhos & Religião & Estado civil \\
\hline Rita & 39 & Superior & Contrato & 2 anos e 6 meses & 2 & Evangélica & Casada \\
\hline Claudia & 32 & Superior & Contrato & 2 meses & 2 & Católica & Solteira \\
\hline Kátia & 21 & Superior & Contrato & 4 meses & Não & Evangélica & Solteira \\
\hline Rosa & 43 & Médio completo & Contrato & 30 dias & 1 & Católica & Relação estável \\
\hline Mary & 40 & Médio completo & Contrato & 1 ano e 6 meses & 2 & Católica & Solteira \\
\hline Rena & 55 & Médio completo & Efetiva & 18 anos & Não & Católica & Divorciada \\
\hline Nazaré & 53 & Médio completo & Efetiva & 32 anos & 1 & Católica & Relação estável \\
\hline Antônio & 53 & Superior & Efetivo & 24 anos & 1 & Católico & Casado \\
\hline Paulo & 25 & Superior & Efetivo & 1 ano e 6 meses & 1 & Cristão & Relação estável \\
\hline Jussimar & 51 & Superior & Efetivo & 18 anos & 2 & Espírita & Casado \\
\hline
\end{tabular}

Nota: Dados sociodemográficos. Os educadores foram nomeados com nomes fictícios.

\section{Procedimento de Coleta e Análise dos dados}

Para o desenvolvimento deste estudo, a primeira providência foi obter autorização judicial para realização de visitas sistemáticas à instituição de acolhimento, o que favoreceu o livre acesso às dependências da instituição e aos participantes da pesquisa. Em seguida o estudo teve aprovação do comitê de ética em pesquisa com seres humanos sob o parecer 568.256.

Para a coleta de dados, foram marcados encontros com os educadores, e foi respeitado seus horários e disponibilidades/intervalos de trabalho para não prejudicar o cuidado e rotina das crianças. As entrevistas foram gravadas em um celular e realizada a transcrição dos áudios na íntegra e todos os participantes assinaram o TCLE, que traz informações sobre a pesquisa e sobre seus direitos como participante.

As informações das entrevistas foram sistematizadas a partir da análise de conteúdo da Bardin (2011) com criação de eixos temáticos, construída a partir da leitura flutuante e sistematização. A análise dos resultados foi organizada em três eixos temáticos que incorporaram as categorias de análise do conteúdo: eixo 1: percepção do acolhimento institucional; eixo 2: cuidado institucional da criança; eixo 3: vínculo afetivo no acolhimento institucional.

\section{Resultados e Discussão}

\section{Percepção do Acolhimento Institucional}

No referido eixo serão discutidas as percepções dos educadores sobre o acolhimento provisório e como os mesmos percebem a situação da criança acolhida. Tal dado é importante para verificar possíveis influências no fortalecimento ou fragilidade na construção dos vínculos afetivos entre o educador e a criança. $\mathrm{Na}$ análise de conteúdo foram identificadas as seguintes falas: "a gente fala em abandono", "maus tratos", "elas estão passando", "situação de risco", "a gente pensa em acolher".

Para esses profissionais, a medida de acolhimento representou um aspecto positivo para as crianças e que garantiu os direitos dos acolhidos que estavam naquele momento em situação de risco, abandono ou maus tratos. A institucionalização foi entendida como medida protetiva e necessária quando acontece alguma violação de direito no percurso de vida das crianças. Alguns profissionais, entretanto, perceberam que o acolhimento não seria um ambiente saudável para o desenvolvimento das mesmas, conforme observou o educador Antônio: "O abrigo não é um espaço para as crianças se desenvolver, as crianças estão aqui até por algumas situações, né!? Por o que aconteceu no percurso da vida". A afirmativa do educador está ancorada na ideia de que o espaço de acolhimento não seria um ambiente promotor de desenvolvimento para a criança. Por mo- 
tivos culturais e sociais, pode-se inferir que o ambiente institucional ainda é visto por alguns educadores como um lugar de dificuldades e de poucas perspectivas (Cruz, Pedroso \& Cavalcante, 2018; Diniz, Assis \& Souza, 2018).

O acolhimento institucional é concebido pelos educadores como um ambiente de garantia de direitos que deveria atender as necessidades das crianças e adolescentes que sofreram alguma situação de risco. Tal concepção é identificada na fala da educadora Nazaré: "Bem, eu acho que é garantia de direitos. Para aquelas crianças estão em vulnerabilidade social, por negligência, abandono, maus tratos e esse acolhimento perante a lei, o Município tem que garantir". O acolhimento institucional representa uma medida importante para as crianças, e mesmo que não fique perceptível a noção de que o espaço deveria promover o desenvolvimento infantil é fator necessário para o ambiente institucional (Guedes \& Scarcelli, 2014).

Referente a isso, o estudo de Cavalcante (2008) afirma que o espaço de acolhimento deveria ser um ambiente de promoção ao desenvolvimento da criança, que pode oferecer amadurecimento biológico e psicológico infantil, e por mais que não seja um ambiente familiar, a instituição deveria garantir, a partir das normas e diretrizes técnicas, a promoção de saúde física, higiene, desenvolvimento emocional, relações interpessoais, dinâmicas de relacionamento que ajudam a criança a manter um desenvolvimento saudável no momento de cuidados substitutos. Uma educadora afirmou que o acolhimento seria um contexto positivo, uma casa que acolhe as crianças em um momento de risco e necessidade. Por mais que os educadores não observem:

O acolhimento institucional é uma coisa boa que veio para as crianças, porque elas são retiradas num momento de risco. Sobre algum momento que elas estão passando, e o acolhimento acolhe essas crianças e é o momento em que elas estão mais precisando. (Rita, educadora).

O educador é uma peça importante na promoção de saúde física e mental dos acolhidos que precisam acreditar no potencial do seu trabalho para executá-lo com dedicação e zelo. Sendo assim, a percepção de que o ambiente ajuda a criança em um momento necessário faz com que o trabalho se desenvolva com mais perspectiva (Golin \& Benetti, 2013).

\section{Cuidado Institucional da Criança}

No referido eixo será analisado como os educadores percebem o cuidado com a criança, a proteção especial vinculada à instituição e como avaliam a referência familiar no cuidado. A percepção sobre cuidado foi vinculada a um trabalho que deve oferecer higiene, alimentação, saúde física e atenção à criança, alguns dos educadores relataram que o cuidado disponibilizado às crianças da instituição era similar aos cuidados que destinavam aos seus filhos.

O cuidado afetivo torna-se importante na vida de um sujeito em formação psíquica Bowlby (2006). O apego pode ser descrito como uma das funções de desenvolvimento psicológico para crianças pequenas que precisam de um suporte para o seu desenvolvimento maturacional. Toda relação começa de um investimento (Bowlby, 2006) e busca na relação interpessoal com o outro, uma maneira de criar e manter os laços de afetividade. Com isso, o autor afirma que, após o investimento afetivo, o próximo sentimento de ligação entre criança e seu cuidador é o amor, que é representado pelo vínculo afetivo em si.

$\mathrm{Na}$ fala dos educadores sobre apego e relação de cuidado com as crianças, os mesmos informaram que percebem um sentimento diferente em relação às crianças e que muitas vezes não sabem explicar. O educador Jussimar apontou que é comum o sentimento de apegar-se a alguma criança, conforme pode observar em seu relato:

"É, a gente se apega sim. São crianças de dois, três meses, de um ano. Fica aquele sentimento, né? Ressalto, agradável, bom, a gente sempre tem assim um, uma afinidade com alguma criança". A concepção de que o apego com as crianças existe, acaba por favorecer a proximidade da relação entre eles e, com isso pode promover o sentimento de uma base segura para o desenvolvimento da criança.

Neste caso, o apego identificado no adulto é um sentimento direcionado à criança pequena que existe de forma natural, sendo uma escolha inconsciente, o qual se torna viável se ambas as partes apresentarem afinidade ao sentimento que vem com a demonstração de comportamentos, sendo que para isso, ambos precisarão estar em sintonia no ambiente. Dessa forma, o que faz a criança criar uma disposição de apego em direção a esse alguém são os comportamentos emitidos por ela e observados pelo adulto, assim como aceitos por ele. Com isso, no momento que o educador permite o sentimento de apegar-se, a criança retribui com emissão de comportamento, como por exemplo, o sorriso, o jogar de um brinquedo, as expressões de satisfação e o afeto (Cecílio, 
Borges \& Scorsolini- Comin, 2018; Kappler \& Mendes, 2019; Lemos, Gechele \& Andrade, 2017).

Para os profissionais, o apego ocorre como algo gradual e peculiar ao seu trabalho, da mesma forma que se apegam às pessoas que residem numa casa. Os mesmos associaram o apego como uma base que constitui as relações no ambiente de uma família, e por isso, no acolhimento não seria diferente. Existe um cuidado familiar que é reflexo das experiências com seus filhos, conforme aponta o relato:

A minha filha eu tenho cuidado, protejo, etc, tal... E assim também como as crianças daqui. Eu acho que elas têm que ter esses cuidados também, né!? Tem que ter esse carinho, tem que proteger, tem que, é, essas crianças daqui elas são filhos né!? Mas a gente tem uma relação. A gente acaba se apegando mesmo e tal, se envolvendo, se doando. (Antônio, educador)

O educador relacionou o apego à sua base de experiência familiar e à possibilidade de cuidar como se fossem filhos. Relatou sobre a impossibilidade de não criar esse vínculo com a criança acolhida, pois, se apega e cria um sentimento, uma relação que, segundo Moura (2012), torna a função de cuidador mais íntima, promotora de saúde mental para as crianças e de condições de ressignificar traumas vivenciados no desligamento com as suas famílias de origem.

O apego é fundamental para a aproximação da criança e do educador que se dispõe a fornecer o carinho e afeto na relação profissional. Bowlby (2002/2006) aponta que o ambiente familiar é o primeiro registro inconsciente da criança para suas futuras interações e a partir do que já foi vivido pela criança em suas experiências, a mesma se comportará com seus pares de referências e terão condições saudáveis de criar, manter e romper os vínculos nas próximas fases do desenvolvimento.

Vínculo afetivo no acolhimento institucional

Neste eixo analisado foi incorporada a percepção dos educadores sobre como os mesmos formam e mantém os vínculos afetivos com as crianças acolhidas. Também foi analisado como os profissionais lidam com a angústia de separação quando as crianças são desligadas da instituição.

O vínculo é um sentimento importante para a relação e que ajuda no cuidado com as crianças. Alguns educadores defenderam a ideia de que deve ocorrer apenas no ambiente institucional, por se tratar de uma forma de trabalho. Vincular-se a alguém pode ser descrito como estar ligado à outra pessoa. Nesse sentido, criar um vínculo pode ser caracterizado como um processo de formação de importantes sentimentos por parte de alguém para outro ser. Bowlby (2006) diz que o vínculo representa fonte inerente de ligação entre as pessoas nos primeiros anos de vida e terá total relevância depois na vida adulta.

Nesse processo, o cuidado e o apego podem ser vistos como parte da formação de proximidade, zelo e atenção entre uma pessoa e outra. Ou seja, são funções diferentes, mas que estão ligadas pelo aporte emocional de cada sujeito. O cuidado pode ser atribuído as várias características das relações humanas, mesmo aquelas mais instintivas como alimentar, fornecer higiene e dar banho. Dessa forma, o vínculo seria uma extensão, um prolongamento mais profundo do cuidado e do apego meramente instintivo que ultrapassaria o desejo de cuidar e de fornecer as condições essenciais para alguém.

Pode-se dizer que o cuidado e o vínculo estão ligados ao sentimento de amor que cada sujeito possui por alguém como objeto amado (Bowlby, 2006). Sobre o cuidar e criar vínculos, o discurso dos educadores esteve pautado na impossibilidade de não criar vínculos, por se tratar de crianças. Como podemos observar no relato da educadora Rita:

É muito difícil não criar um vínculo. Muito difícil, porque são crianças que eu entendo que precisa ter o mínimo de afeto possível. Só se a pessoa for muito seca pra não ter esse, não dar um pouco de carinho e a atenção.

A educadora associou o vínculo afetivo como uma proposta de dar afeto, carinho e atenção. Sentimentos importantes para a relação com a criança, como a necessidade de oferecer o melhor de si, o cuidado mais atencioso possível para aqueles que, naquele momento, precisavam de afeto e cuidado. Nesse sentido, Bowlby (2006), Golin (2010) e Moura (2012) afirmam que a formação do vínculo por parte de um adulto acontece e se fortalece na convivência diária, na expectativa de aproximar a relação e promover saúde e desenvolvimento para a criança e para si. Como observamos na fala da educadora Mary:

Um vínculo afetivo a gente tem esse vínculo esse vínculo afetivo, porque, a gente ta no dia a dia com as crianças. A gente tem que fazer um carinho na criança. A gente recebe esse carinho deles também, por que eles são carinhosos. Então, esse vínculo eu acho muito importante até pro desenvolvimento deles.

A formação de um vínculo está ligada à proximidade e à convivência do dia a dia. Essa afirmativa está 
diretamente ligada à concepção da educadora. Além do fato de estar na rotina do educador, a formação desse vínculo traz a possibilidade de um resgate de sentimentos que a criança já possui registros de um lar, de família e de outros sujeitos que já fizeram parte da sua trajetória (Bowlby, 2006; Golin e Benetti, 2013).

No discurso dos educadores em relação aos sentimentos ligados ao desligamento vivenciado no trabalho, no dia a dia deles e das crianças em acolhimento, observou-se a percepção dos educadores diversificada. Alguns se emocionaram ao falar de tais experiências vividas nessa profissão, enquanto outros profissionais outros profissionais encaram esse momento como algo natural e esperado veja na fala da educadora Rosa: "A gente tem que encarar com naturalidade, porque aqui é um, um local que elas estão só de passagem, elas estão cuidando dos traumas delas. A gente tem que ta ciente que elas não vão ficar aqui pra sempre".

A educadora supracitada enfatiza como comum esse momento, pois ela já possui a consciência de que as crianças não ficariam para sempre na instituição e que o espaço de acolhimento é um local provisório para que as crianças cuidem dos seus traumas. Guedes e Scarcelli (2014) apontam que a concepção dos educadores sobre o acolhimento pode influenciar no propósito de seu trabalho, pois, existe uma visão mistificada e cultural de que o espaço de acolhimento seria um ambiente de mazelas, de crianças problemáticas e traumatizadas.

Essa ideia está presente no discurso da educadora e talvez por isso, seja mais fácil buscar amparo à razão do que na emoção quando se discute a questão do desligamento. Porém, vale ressaltar que existem outros discursos sobre o desligamento que apontam esse momento com tristeza, apego e choro na saída das crianças, na fala da educadora Claudia: "a gente se apega muito. Ai a gente fica triste, às vezes até chora um pouquinho, de saudade. Mas depois, tem que ser assim, é, nosso trabalho tem que ser assim". O relato da educadora Rena aponta que a saída da criança gera angústia e faz o educador sentir falta. Essa angústia se reflete até em sonhos, como podemos observar na fala:

A gente sente falta principalmente, eu já acordei a noite desesperada. É que eu dormi e falei: mãe, cadê o Juquinha que não ta aqui na cama? Eu pensei que eu estava, que eu tinha, estava fazendo o Juquinha dormir e eu tinha cochilado. Aí acordei desesperada mãe, cadê o Juquinha? - Que Juquinha, menina? - O Juquinha que levantou da cama, eu estava fazendo ele dormir? - Não menina, tu ta em casa.

A educadora relatou que sentia falta, que já chegou a sonhar que estava na instituição, quando na verdade estava em sua casa e imaginou a saída de uma criança. Ficou evidente a angústia de separação, uma vez, que a relação entre educadores e criança é intensa e diária, como disse a educadora Rosa no trecho:

A gente sente uma falta assim, quando a gente vai, a gente vai embora. Quando a gente sai no portão eles dizem - não tia, não vai, fica mais um pouco, fica mais um pouco. Então a gente sente falta. É o dia todo. A gente chega 7:00 horas da manhã e sai 19:00 horas da noite. Sente falta sim.

Observa-se uma concepção de que as práticas rotineiras fortalecem o vínculo e a relação entre as partes, pois, como diz a educadora, existe a convivência do dia a dia, uma intensidade de sentimentos que envolvem o trabalho e a prática de cuidado, que acaba com a tristeza no final do expediente. Tinoco e Franco (2011) apontaram essa ideia do desligamento na saída da instituição e do sofrimento vivenciado pelos educadores como parte do luto institucional. À medida que as crianças saem, os profissionais sofrem e buscam subsídios para continuar seu trabalho com as demais crianças.

Por esse medo de separação, a angústia pode surgir por meio de sonhos, pensamentos e lembranças. Pode-se ver nas falas citadas anteriormente que a separação para alguns é encarada como algo natural, esperado e parte da profissão, e para outros, a saída das crianças representa sofrimento, angústia e lembranças.

\section{Considerações Finais}

Esse estudo analisou a percepção de educadores de instituições de acolhimento infantil sobre vínculos afetivos com crianças em acolhimento institucional. de acolhimento infantil, sobre vínculos afetivos com crianças em acolhimento institucional. Também, foi discutida a atuação profissional desses educadores, a entrada e saída das crianças do espaço de acolhimento, a formação, manutenção e rompimentos dos vínculos afetivos nesse contexto.

As análises apontaram que os educadores formam, mantém e criam vínculos com as crianças acolhidas. Uma parte deles procurou proteção em si mesmo, na tentativa de não manter proximidade com as crianças para não sofrer com o desligamento delas. Outros acreditaram que é difícil não se vincular, pois se trata de crianças que 
passaram por traumas, negligência, problemas emocionais, abandono, mazelas e sofrimentos familiares.

Os educadores acreditam que a criança que está acolhida passou a viver na instituição por não existir alternativa, por se tratar de uma garantia de direitos e até mesmo por ser um "mal necessário". Segundo eles, os impactos da institucionalização podem ser minimizados com a promoção de novas relações afetivas e com os cuidados zelosos que são oferecidos às crianças. A concepção dos educadores tornou-se fundamental para a compreensão da atuação que cada um promove em suas rotinas institucionais, pois uns tendem a criar e manter os vínculos e outros procuraram proteção na negação dos sentimentos direcionados às crianças na tentativa de não sofrer após a sua saída.

Dessa maneira, podemos dizer que o cuidado, a relação com as crianças e os vínculos afetivos estão diretamente ligados com a atuação profissional e a subjetividade de cada um. Os discursos dos educadores divergiram entre a impossibilidade de não criar vínculos com as crianças e os prejuízos que esse vínculo pode trazer na relação e no trabalho desempenhado na instituição, principalmente no momento do desligamento delas.

Esse processo de vinculação promove afeto, proximidade, afeição, zelo, angústia e sofrimento para os educadores que se apegaram a crianças na entrada na instituição e também no momento da reintegração familiar ou da adoção. Esse sentimento de sofrer pela saída das crianças pode ser minimizado quando as mesmas retornam para suas a famílias ou são reintegradas em uma família que dará o suporte, carinho e afeto necessários para o bem-estar das crianças.

Nesse sentido, a relação entre os que cuidam e os que são cuidados tornam-se promotora de um resgate de sentimentos entre as crianças, o ambiente e os educadores. A característica singular dessa pesquisa está ligada a percepção dos educadores sobre os vínculos afetivos, em dar voz a um público que atua diretamente com a saúde física e mental de crianças em um espaço que promove desenvolvimento e ao mesmo tempo busca amenizar por meio da relação estabelecida o sofrimento de estar longe de casa.

Assim como o vínculo pode promover angústia, sofrimento, saudade e tristeza para a rotina de trabalho dos educadores, os mesmos afirmaram que a cada saída, a dor traz uma proteção para a formação dos próximos vínculos com as próximas crianças. Além disso, há edu- cadores que acreditam que o vínculo acontece de forma inconsciente e é inerente ao cuidado. Outros sentem que podem controlar esse sentimento por meio da autoproteção e da distância.

Os principais limites encontrados para o desenvolvimento deste estudo foram: a impossibilidade de generalização dos resultados e as dificuldades de realizar as entrevistas em espaços isolados, sem as interferências dos acolhidos. Para pesquisas futuras, sugere-se que sejam investigados os vínculos afetivos entre os acolhidos e os técnicos das instituições e a percepção dos familiares sobre o que caracteriza o vínculo afetivo e como eles percebem isso na relação com as crianças.

\section{Referências}

Barros, N. S., \& Naiff, L. A. M. (2015). Capacitação para educadores de abrigo de crianças e adolescentes: identificando representações sociais. Estudos e Pesquisas em Psicologia, 15(1), 240-2599. doi: 10.12957/epp.2015.16073

Bowlby J. (2006). As origens do apego. Uma base segura: aplicações clinicas da teoria do apego. Porto Alegre: Artes Médicas.

Bowlby, J. (2002). Apego: a natureza do vínculo. São Paulo: Martins Fontes.

Bowlby, J. (2006). Cuidados maternos e saúde mental. São Paulo: Martins Fontes (Original publicado em 1969).

Bowlby, J. (2006). Formação e rompimento dos laços afetivos. São Paulo: Martins Fontes.

Brasil. (2013). Relatório da infância e juventude - resolução $n^{\circ}$ 71/2011: Um olhar mais atendo aos serviços de acolhimento de crianças e adolescentes no País. Brasília: Conselho Nacional do Ministério Público.

Brito, C. O. de, Rosa, E. M., \& Trindade, Z. A. (2014). O processo de reinserção familiar sob a ótica das equipes técnicas das instituições de acolhimento. Temas em Psicologia, 22 (2), 401-413. doi:10.9788/TP2014.2-11.

Calcing, L., \& Benetti, S. P. (2014). Caracterização da saúde mental de crianças e adolescentes em acolhimento institucional. Psico, 45 (4), 559-567. doi: https://doi.org/10.15448/1980-8623.2014.4.13629

Cavalcante, L. I. C., Magalhães, C. M. C., \& Pontes. F. A. R. (2007). Institucionalização precoce e prolongada de crianças: discutindo aspectos decisivos para o desenvolvimento. Aletheia, (25), 20-34. Retirado de http://www.ufpa. br/led/documentos/Institucionalizacaooprecoceeprolongadadecriancas.pdf.

Corrêa, L. da S. (2011). Concepcões de desenvolvimento e práticas de cuidado à criança em ambiente de abrigo na perspectiva do nicho desenvolvimental (Dissertação não publicada). Programa de Pós Graduação em Teoria e Pesquisa do Comportamento. Universidade Federal do Pará, Brasil.

Cruz, E. J. S., Cavalcante, L. I. C., \& da Silva Pedroso, J. (2018). Mães, avós e cuidadoras de crianças institucionalizadas: conhecimentos sobre desenvolvimento na infância. Psicologia Argumento, 36(94), 527-545. doi: http:// dx.doi.org/10.7213/psicolargum.36.94.AO06

Diniz, I. A., Assis, M. O., \& de Souza, M. F. S. (2018). Crianças institucionalizadas: um olhar para o desenvolvimento socioafetivo. Pretextos-Revista da Graduação em Psicologia da PUC Minas, 3(5), 261-285.

Golin, G. (2010). A interação entre a criança abrigada e seu cuidador: o vínculo na institucionalização (Dissertação não publicada). Programa de Pós Graduação em Psicologia. Universidade do Vale do Rio dos Sinos, Brasil.

Golin, G., \& Benetti, S. P. C. (2013). Acolhimento precoce e o vínculo na institucionalização. Psicologia: Teoria e Pesquisa, 29 (3), 241-248. doi: http:// dx.doi.org/10.1590/S0102-37722013000300001

Guedes, C. F., \& Scarcelli, I. R. (2014). Acolhimento institucional na assistência à infância: o cotidiano em questão. Psicologia \& Sociedade, 26 (n ${ }^{\circ}$ especial), 58-67. doi: http://dx.doi.org/10.1590/S0102-71822014000500007 
Kappler, S. R., \& Mendes, D. M. L. F. (2019). Trocas afetivas de crianças em acolhimento institucional. Psicologia: Ciência e Profissão, 39. doi: https://doi. org/10.1590/1982-3703003184527

Leite, M. M. (1997). A infância no século XIX segundo memórias e livros de viagem. In M. Freitas (Ed.), História social da infância no Brasil (pp. 17-50). São Paulo: Cortez.

Magalhães, C. M. C., Costa, L. N., \& Cavalcante, L. I. C. (2011). Percepção de educadores de abrigo: o seu trabalho e a criança institucionalizada. Revista Brasileira de Crescimento e Desenvolvimento Humano, 21 (3), 1-14. Retirado de http://pepsic.bvsalud.org/scielo.php?script=sci arttext\&pid $=\mathrm{S} 010412822011000300008$

Marcílio, M. L. (1998). História Social da Criança Abandonada. São Paulo: Hucitec. Medeiros, B. C. D. D., \& Martins, J. B. (2018). O estabelecimento de vínculos entre cuidadores e crianças no contexto das instituições de acolhimento: um estudo teórico. Psicologia: Ciência e Profissão, 38(1), 74-87. doi: https:// doi.org/10.1590/1982-3703002882017

Moura. G. G. (2012). "Quem não pega, não se apega": o acolbimento institucional de bebês e as (im) possibilidades de construção de vinculos afetivos. (Dissertação não publicada). Faculdade de Filosofia, Ciências e Letras de Ribeirão Preto, da USP, São Paulo, Brasil.
Penso, M. A. \& Moraes, P. J. F. de S. (2016). Reintegração familiar e múltiplos acolhimentos institucionais. Revista Latinoamericana de Ciencias Sociales, Niñez. y Juventud, 14 (2), 1523-1535. doi: 10.1590/1413-81232014201.19872013

Pontes, F. A. R., Silva, S. S. C., \& Magalhães, C. M. C. (2007). Teoria do apego: elementos para uma concepção sistêmica da vinculação humana. Aletheia, (26), 67-79. Universidade Luterana do Brasil. Retirado de http://www. redalyc.org/articulo.oa?id=115013567007.

Rossetti-Ferreira, M. C. (2013). Interação entre fatores biológicos, socioeconômicos e culturais no desenvolvimento mental e desempenho escolar da criança desnutrida. Cadernos de Pesquisa, (29), 37-48.

Siqueira, A. C., \& Dell'Aglio, D. D. (2006). O impacto da institucionalização na infância e na adolescência: uma revisão de literatura. Psicologia \& sociedade, 18(1), 71-80. Doi: https://doi.org/10.1590/S0102-71822006000100010

Tinoco, V., \& Franco. M. H. P. (2011). O luto em instituições de abrigamento de crianças. Estudos de Psicologia, 28(4), 427-434. doi: https://doi. org/10.1590/S0103-166X2011000400003

Submetido em: 11-5-2021

Aceito em: 7-10-2021 